\title{
ESPAÇO SEMIÓTICO EM DIÁLOGOS E FRONTEIRAS $^{1}$
}

\section{SEMIOTIC SPACE IN DIALOGUES AND BOUNDARIES}

IRENE MACHADO *

RESUMO: Nada traduz de modo mais efetivo a noção de ambiente cultural do que o processo de continuidade. Nada materializa de modo mais radical o continuum semiótico do que a fronteira que une e situa em diálogo os sistemas culturais em confronto. No contexto do pensamento semiótico da cultura, a dialogia se desenvolve na arena dos espaços de confronto em que os sistemas de signos se encarregam de promover os contatos e encontros culturais. Ainda que os conceitos de fronteira e dialogia, quando inseridos no processo da semiose cultural, explicitem potências de intensidades equivalentes, o ambiente conceitual de Lótman não conta diretamente com os pressupostos de Bakhtin para a conceptualização do espaço semiótico da semiosfera. Que linhas conceituais se encarregaram de aproximar e distanciar tais conceitos e até que ponto nos é lícito operar a continuidade? Tais são os pontos que se espera examinar no estudo.

10 presente trabalho foi apresentado como conferência no III Simpósio Internacional de Estudos Discursivos, Assis, 2014. Com o tema Humanidade(s) dialógica(s), abriu espaço para a mesa Semiótica da cultura: diálogos entre Lótman e Bakhtin.

* Docente da USP - Universidade de São Paulo. E-mail: irenemac@uol.com.br. 
PALAVRAS-CHAVE: Dialogia. Espaço semiótico. Fronteira. Conflito. Discurso. Texto.

\begin{abstract}
Nothing translates in a more effectively fashion the notion of cultural environment than the process of continuity. Nothing materializes in a more radical fashion the semiotic continuum than the boundary that joins and places in dialogue the cultural systems in confrontation. In the context of the semiotic thought about culture, dialogy is developed inside the arena of confrontational spaces in which sign systems are responsible for contacts and cultural meetings. The concepts of boundary and dialogy translate almost equivalent intensities of power when inserted in the process of cultural semiosis; notwithstanding, Lotman's conceptual field of semiosphere is not directly dependent on Bakhtin's assumptions. What conceptual lines have been responsible for approaching and distancing such concepts? To what extent is it licit to operate continuity? These are the points that are expected to be examined in the study.
\end{abstract}

KEYWORDS: Dialogy. Semiotic space. Boundary. Conflict. Discourse. Text.

\title{
Apresentação do problema: Texto como tradução transformadora de experiências
}

O que Iúri Lótman e a semiótica da cultura têm a dizer para os Estudos discursivos? Evidentemente que o fato de Lótman ter conferido ao texto a condição de problema central da semiótica da cultura suscita um campo de inferências que o aproxima das que Mikhail Bakhtin desenvolveu a respeito 
do texto. Contudo, tal aproximação anuncia mais um problema do que uma solução.

Tal como Bakhtin, Lótman considera o texto a fundação do pensamento que entende as transformações das coisas em signo, visto que o texto se constitui a partir da "energia formativa" (BAKHTIN, 1989, p. 16) de tudo aquilo dotado de voz nos sistemas semióticos da cultura. Energia capaz de sustentar a trama sem a qual nenhuma cultura sobrevive, afinal, segundo tal concepção, cultura implica variedades semiósicas, constante modificação e, sobretudo, geração de novas formas culturais. Isso para não falar que cultura implica vínculo e movimento para o outro e para o imprevisível no fluxo da continuidade de tudo o que se movimenta. Como insiste Lótman em muitos de seus escritos, um sistema isolado simplesmente não existe.

Quem entra em contato com o conceito lotmaniano de texto (LOTMAN, 1996a; 1996b; 1996c), amadurecido nas teses da escola de Tártu (IVANOV et al, 1998), certamente opera em sua mente todo um caminho que leva a Bakhtin (1989), afinal, a noção de energia formativa está presente nas duas concepções. Há, contudo, um ponto de radical distanciamento entre os dois teóricos russos. Enquanto Bakhtin entende que a energia formativa geradora do texto se constitui a partir da relação entre autor e personagem e também dos gêneros, particularmente, na dinâmica dos gêneros discursivos que movimentam a vida da linguagem na cultura, Lótman segue numa outra direção. Para o semioticista da escola de Tártu, energia formativa diz respeito à força construtiva que transforma as coisas do mundo em cultura. Nesse sentido, o texto não se constitui pela linguagem mas sim o contrário: o texto precede a linguagem e a constitui (LOTMAN, I., 1996c, p. 87). Tampouco se pode restringir a energia formativa aos gêneros 
discursivos visto que somente aos sistemas de signos verbais e àquilo que gravita em torno da palavra seria atribuída a capacidade de funcionamento como dinamismo de alimentação da força motriz da cultura, e Lótman não conta com essa premissa. Na verdade, a energia formativa do texto que lhe confere capacidade de força motriz de diferentes sistemas culturais e de semiose corresponde ao mecanismo semiótico que Lótman define como tradução.

Seguindo a tradição de pensamento de poetas como Viélimir Khliébnikov e Aleksei Krutchônikh o pensamento de Lótman se mostra sintonizado com uma noção que fertilizou o campo conceitual do pensamento crítico-criativo do início do século XX na Rússia. Trata-se da noção de "palavra como tal" (slova kak takovoe). Em seus estudos sobre o fonema como feixe de traços distintivos acusticamente, Roman Jakobson consolidou a máxima do "som como tal" em seus estudos sobre a relação entre som e sentido. Já o artista plástico Kasimir Maliévitch explorou as formas da "luz como tal" em seus trabalhos concebidos como suprematismo (MACHADO, 2008). Com base em tal tradição, a noção de Lótman sugere, segundo o nosso entendimento, o "texto como tal". 
Gravura 1 - Slovo kak takovoie (A palavra como tal) de K. Maliévitch para a capa do livro

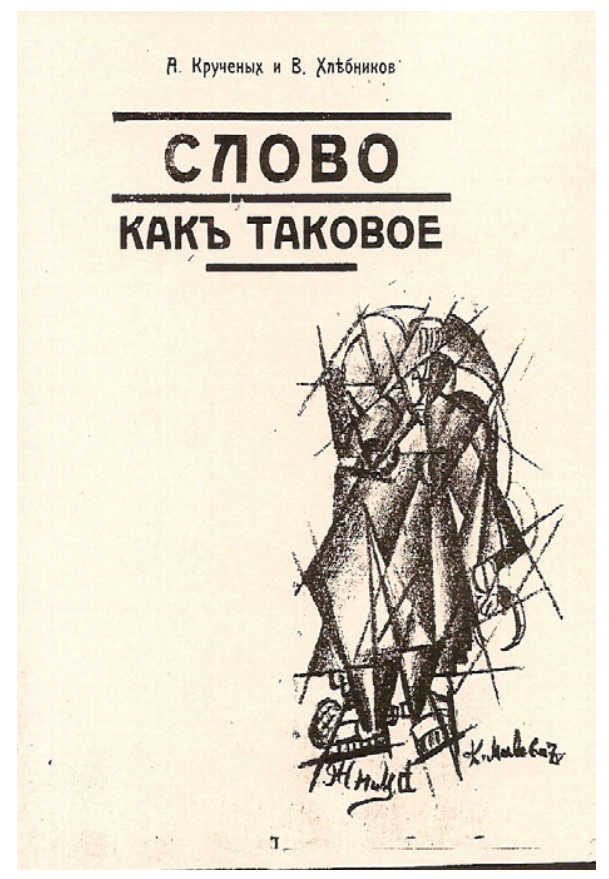

Fonte: A. Krutchônikh \& V. Khliébnikov (1913)

De acordo com nossa hipótese, ainda que não se vincule diretamente à tradição poética do construtivismo russo, a noção de "texto como tal" não nega sua vinculação ao conceito da "coisa em si" (Ding an sich), no contexto da revisão crítica que Mihhail Lótman empreende da formulação de seu pai (LOTMAN, M., 2000, p. 23-46). No seu entendimento, a noção do texto como coisa em si ou texto como tal tem ficado à margem dos estudos sobre a centralidade do texto na semiótica da cultura. Firmado na epistemologia kantiana, serviu de base para a metodologia cibernética onde Lótman (pai) se orientou para fundamentar sua concepção. Nesse sentido, texto 
concentra uma força motriz - a tradução - que o faz funcionar como uma caixa preta: "sabemos qual é o input e o output do sistema mas, em princípio, é impossível ver o que está acontecendo no interior" (LOTMAN, M., 2000, p. 26).

0 texto dotado do mecanismo de tradução mostra-se capaz de transformar aquilo que é dado em algo criado e, por conseguinte, culturalizar seu entorno (LOTMAN, I., 1996b; 1990a). Com isso, a informação dispersa no cosmos se torna cultura. A tradução revela a experiência transformadora da vida no universo em experiência de cultura. Evidentemente que pelo viés da tradução como transformação de grandes esferas da experiência, a magnitude do conceito de texto em Lótman extrapola os termos da comparação com o conceito bakhtiniano. Diríamos, pois, que estamos diante de concepções de diferentes grandezas.

Quando Lótman entende o texto como força motriz de funcionamentos ele está longe de afirmar que os textos sejam sistemas de signos já constituídos. Desestabiliza a clássica noção de mensagem codificada, pronta para ser descodificada. Para Lótman, o texto pensado a partir da energia formativa cuja força motriz é a tradução se define graças ao trabalho de sistemas de signos no processo de seu funcionamento. Texto é função, como formularia num clássico estudo elaborado em parceria com A. M. Piatigórski (LOTMAN; PIATIGORSKI, 1998, p. 163-174). 0 texto permite olhar para o intervalo de um deslocamento ou de uma transformação e acompanhar o movimento deflagrado no interior dessa "caixa-preta", o que nas palavras de Lótman significa:

[...] o texto se apresenta diante de nós não como a realização de uma mensagem em uma só linguagem qualquer, mas como um complexo dispositivo que guarda vários códigos, capaz de transformar as mensagens recebidas e de gerar no- 
vas mensagens, um gerador informacional que possui traços de uma pessoa com um intelecto altamente desenvolvido. (LOTMAN, I., 1996b, p. 82).

Como se observa, os mecanismos de input e output, de codificação e descodificação, e tudo aquilo que comumente se atribui à operação de equivalência entre uma língua de partida e uma língua de chegada, pouco ou quase nada dizem a respeito do fenômeno cultural da tradução. Lótman, assim como Jakobson, considera que na tradução existe uma busca por equivalência, contudo, trata-se de um diálogo entre variáveis com valências potencialmente diferentes. Isso porque os signos que entram para o processo de tradução são sistemas de cultura o que implica dizer que a tradução opera com elementos em diferentes esferas de constituição, inclusive com aqueles provenientes de regiões de intraduzibilidade e imprevisibilidade que estão muito longe de firmar correspondências diretas. 0 texto assim compreendido é manifestação elementar daquilo que Lótman formula como semiosfera de modo a dimensionar o grande embate que sustenta os sistemas culturais como processos do espaço-tempo.

Chegamos assim a um entrecruzamento muito mais favorável a especular sobre o conceito de texto como um modelo dialógico, respeitando-se o viés discursivo de Bakhtin e avançando para o processo tradutório da noção lotmaniana. Não se trata, contudo, de contrapor formulações, mas de encontrar nelas convergências e divergências. Nesse sentido, trata-se de enfrentar o texto como uma dimensão espaçotemporal e exotópica cujo movimento para fora se abre para o imprevisível das relações dialógicas. Nele o campo de formulações bakhtinianas sobre o cronotopo e a extraposição (BAKHTIN, 1988; 1989) fertilizaram o terreno das concepções de Lótman, deixando aflorar a radicalidade do entendi- 
mento do texto no espaço semiótico da semiosfera (LOTMAN, I., 1984, 1996a; LOTMAN, Y., 1990b).

Semiosfera corresponde a uma visão ou modelo de cultura que considera sobretudo o movimento dos sistemas de signos da cultura em sua constante transformação ou tradução. Nesse sentido, semiosfera é um conceito com implicações cronotópicas decisivas para o seu funcionamento.

Ora, não podemos tratar da expansão do texto rumo à semiosfera sem antes reconhecer que o espaço-tempo se tornou um problema semiótico igualmente fundante do dialogismo. Em seus estudos de poética histórica Bakhtin submete a uma rigorosa inspeção teórico-conceitual os diferentes processos de transformação da experiência em representação estética, onde pontos de vista espaço-temporais e exotópicos são transformados plasticamente em modelos de mundo e criações estético-culturais.

Temos aqui colocados os termos de uma outra equação: aquela que entende o espaço semiótico da cultura no âmbito das relações cronotópicas e da exotopia a determinar o funcionamento dos textos de cultura no interior da semiosfera. Trata-se de um circuito de relações que aproxima o conceito de texto lotmaniano aos pressupostos do dialogismo bakhtiniano, sobretudo aos princípios da exotopia (ou extraposição) ${ }^{2}$ e da cronotopia, formulados, em grande parte, nas análises da relação entre autor e personagem tal como criado por Dostoiévski em seus romances.

2 Em estudos anteriores optamos pelo termo extraposição para se indicar a visão externa a um ponto de vista posicionado (MACHADO, 2010). Adotamos aqui exotopia, termo de designação equivalente, adotado por T. Todorov em suas traduções, porque trataremos de relações topológicas não posicionadas necessariamente num campo visual. 


\section{Análise do problema}

\subsection{Dramatização do espaço no princípio dostoievskiano da simultaneidade ${ }^{3}$}

Para ir diretamente ao ponto da questão - o das variantes cronotópicas e exotópicas no espaço semiótico da semiosfera - vou me reportar à novela de Dostoiévski em que a personagem reconstitui a experiência de sua viagem ao estrangeiro de modo a entender o tempo histórico a partir das transformações sociais e políticas construídas numa dimensão espaço-temporal que extravasa a vivência de episódios pitorescos. Em Notas de inverno sobre impressões de verão a personagem confessa suas impressões sobre as cidades europeias conjugadas sob a rubrica de estrangeiro. Se num primeiro momento "impressões" sugerem uma percepção interior, as palavras iniciais do personagem proferidas em termos de hipóteses e inferências desfazem qualquer referência subjetiva, como se pode ler no fragmento que se segue.

Meu Deus, o que não esperava desta viagem! "Vá lá que não examine nada em pormenor", pensava, "mas, em compensação, terei visto tudo, estado em toda parte; e de tudo o que vir ficará uma impressão de conjunto, um panorama geral. Todo o 'país das sagradas maravilhas' vai apresentar-se de uma vez aos meus olhos, a vôo de pássaro, como a Terra da Promissão em perspectiva do alto da montanha". Numa palavra, há de resultar uma impressão nova, magnífica, intensa. (DOSTOIÉVSKI, 1992, p. 190).

Impressão traduz um modo de ver a partir de um ponto,

3 Recorte da análise desenvolvida no ensaio: Forma espacial da personagem como acontecimento estético cronotopicamente configurado (inédito). 
um posicionamento favorável a alcançar o largo espectro de um campo visual. Na verdade, as "impressões" constroem um panorama cuja perspectiva é dada pela visão de grandes latitudes, capazes de operar sínteses espaciais, distanciamentos e generalizações para gerar um espaço de simultaneidades. Com tais panoramas o personagem traduz plasticamente $o$ movimento amplo de suas impressões e embates, como a que surgiu em Berlin: "essa cidade produz em geral uma impressão azeda” (DOSTOIÉVSKI, 1992, p. 190). Sínteses capazes de promover contrapontos tal como o debate de ideias travado no interior de um trem, quando se desloca para Paris, um dos locais mais aguardados. Pensamentos gerados no pensamento, tal como se pode ler nos segmentos cujas aspas foram usadas com função distintiva.

\begin{abstract}
“Meu Deus, que espécie de russos somos nós?", vinha-me por vezes à mente, sempre sentado no vagão. Somos realmente russos? Por que a Europa exerce sobre nós, sejamos quem formos, uma impressão tão forte e maravilhosa, e tamanha atração? Isto é, não falo agora dos russos que lá ficaram, daqueles russos de modesta condição, que se chamam cinqüenta milhões, e a quem nós, que somos cem mil, até agora consideramos com toda a seriedade como sendo ninguém e de quem as nossas tão profundas revistas satíricas ainda hoje zombam, pelo fato de não rasparem as barbas. Não, falo agora do nosso grupinho privilegiado e patenteado. Porque tudo, decididamente quase tudo o que em nós existe de desenvolvido, ciência, arte, cidadania, humanismo, tudo, tudo, vem de lá, daquele país das santas maravilhas! (DOSTOIÉVSKI, 1992, p. 197).
\end{abstract}

Se, por um lado, o posicionamento permite alcançar a amplitude, por outro, cada ponto de vista emergente em cada experiência revela como o espaço contínuo e infinito vivencia 
o tempo em sua atualidade histórica. As impressões se revelam não apenas exotópicas como também cronotópicas. Quer dizer, as impressões imprimem nas experiências de viagem espacialidades distintas que jogam com planos diferenciados de vivências e do que gravita externa ou exotopicamente em relação a eles.

São várias as experiências de espacialização que a personagem vivencia, nos deslocamentos pelas cidades. Incorporadas às suas narrativas entram para a composição de contrastes com as cidades russas, particularmente São Petersburgo, criando escalas de gradientes espaciais. 0 mais acentuado é, sem dúvida, aquele que marca o conflito que é gerado pela sobreposição da condição eslava na condição de estrangeiro. Vale dizer, da transição da cultura russa rumo à civilização europeia e para o tão consagrado mundo do progresso. As impressões assim desenvolvidas definem-se como o cronotopo da experiência estrangeira, síntese de toda a Europa europeia, contra a qual se debate a vivência do eslavofilismo da Europa russa, conforme distinção da própria personagem (DOSTOIÉVSKI, 1992, p. 218). Segundo as impressões de viagem manifestadas por ela, há evidências de modos distintos de o espaço vivenciar o tempo histórico, bem como da maneira que a história se atualiza na enunciação discursiva da personagem.

Em diferentes momentos de suas confissões a personagem se indaga a respeito do confronto entre o russo e o europeu: "Existirá realmente uma associação química, entre espírito humano e o solo pátrio, que torne impossível a alguém separar-se definitivamente deste, e de modo tal que, se dele se separa, acaba sempre por voltar? (DOSTOIÉVSKI, 1992, p. 198).

Assim formulada, a pergunta denuncia a necessidade de refletir sobre a condição exotópica e cronotópica do espaço ao 
abrigar os movimentos da história em suas mais variadas direções. Em outro momento se indaga sobre o movimento não daquele que vai e retorna, mas da dominação europeia que se sobrepõe à própria pátria:

E justamente meditava sobre o tema: de que modo a Europa se refletiu em nós em diferentes épocas, e incessantemente nos forçava a porta para visitar-nos com a sua civilização, e até que ponto nos civilizamos, e quanto de nós se civilizaram até hoje. Agora, eu mesmo estou vendo que tudo isto é como que supérfluo aqui. (DOSTOIÉVSKI, 1992, p. 203).

Ou seja: para viver o tempo histórico e suas transformações, a Europa amplia seus espaços não necessariamente pela expansão territorial, mas pelas intervenções no "espírito do tempo" que sorrateiramente se incorpora à cultura. Tal como ocorreu com a cidade de São Petersburgo, dominada pelo padrão de cidade forjado no continente europeu não russo e, portanto, estrangeiro. Observe-se que o próprio espaço se constitui por um alinhamento que o transcende: a Europa russa que transborda da Europa europeia.

A partir do momento em que o espaço físico das cidades é substituído pela dimensão do estrangeiro, a noção de espaço se funde com o tempo para traduzir a dialogia da pátria em espaços de fronteira com outras línguas e culturas. Estrangeiro é a condição de exotopia e de cronotopia e a própria civilização passa a ser objeto da indagação, sobretudo pelo sistema de valores que passa a se manifestar eticamente. No discurso de nossa personagem, o progresso torna-se o valor ético que passa a ser mensurado cronotópica e exotopicamente, principalmente em sua capacidade de modificar o valor do estrangeiro, como se pode acompanhar no raciocínio. 
Vá lá que ao redor de nós, mesmo agora, nem tudo esteja muito bonito; em compensação, nós mesmos somos tão belos, tão civilizados, tão europeus que o povo tem até náuseas de nos olhar. Atualmente, o povo já nos considera de todo estrangeiros e não compreende uma palavra, um livro, um pensamento nosso, e isto, digam o que quiserem, é progresso. [...] Em compensação, quão convencidos estamos agora de nossa vocação civilizadora, quão do alto resolvemos os problemas, e que problemas: não há solo, não há povo, a nacionalidade é apenas um determinado sistema de impostos, a alma, uma tabula rasa, uma cerinha com a qual se pode imediatamente moldar um homem verdadeiro, um homem geral, universal, um homúnculo: basta para isto aplicar os frutos da civilização européia e ler dois ou três livros. (DOSTOIÉVSKI, 1992, p. 211).

A adoção do padrão civilizatório, porém, não muda radicalmente a cidade que resulta numa sobreposição de padrões. Com isso, reina uma noção de uma experiência ambivalente em transformação e inacabada. 0 tempo deixa rastros que não realizam intervenções definitivas no espaço, resultando, assim, numa construção em devir.

O cronotopo da experiência que se manifesta na novela de Dostoiévski desenvolve uma controversa discussão sobre as relações de tempo e espaço bem como da atualidade do tempo histórico nos espaços e suas atualizações inacabadas. À pergunta central do cronotopo: como o espaço vivencia o tempo? (BAKHTIN, 1988), responde-se: pela exotopia - a vivência contrastante do espaço nas ambivalências da espacialização espaço-temporal do estrangeiro. Dessa percepção Bakhtin procurou extrair tudo o que pôde para articular a sua concepção de forma espacial da personagem como um modelo de mundo ético, porque vinculado a vivências, e estético, por operar traduções plásticas das relações em jogo. 


\subsection{Forma espacial na arena de pontos de vista}

A vivência contrastante do espaço no tempo não marca apenas as grandes experiências históricas mas traduz a experiência estética como obra artística. Isso foi objeto primordial da investigação que seguiu passo a passo a relação entre autor e personagem.

Ainda que num nível bem elementar da obra de arte verbal a personagem se apresente como enfoque da organização discursiva do autor, no âmbito da construção discursiva criada por Dostoiévski, em suas novelas e romances, nenhuma personagem se constitui senão enquanto foco irradiador da imagem de uma linguagem que apenas aparentemente é "do autor". Em outras palavras: em vez de resultado do enfoque do autor, a personagem se organiza em torno de seu próprio discurso que lhe orienta o foco quando estabelece diálogos consigo ou com o outro, onde está incluso o próprio autor. Seja pelo embate, seja pelo confronto, a imagem da linguagem assim elaborada se manifesta em função dos planos discursivos, a um só tempo, posicionados e projetados sob diferentes pontos de vista e, até mesmo, liberados pela reação criativa que distingue a elaboração estética num gesto de superação.

A imagem da linguagem vinculada à relação discursiva mostra-se, por conseguinte, como espaço em que discursos se organizam, se dispersam, mas não se evadem. Se considerarmos que nesse espaço a imagem traduz ideias - consonantes e dissonantes - não é difícil entender o modo pelo qual Dostoiévski chegou à consagração do romance polifônico como modelo artístico de mundo. Também não será difícil entender porque Bakhtin, ao se voltar para as singularidades poéticas do romance polifônico, não hesitou em reconhecer que "Dostoiévski via e pensava seu mundo predominantemente no es- 
paço e não no tempo." (BAKHTIN, 1981, p. 22): os seus personagens são projeções de confrontos e ideias cronotópica e exotopicamente configuradas. Por conseguinte, será menos problemático admitir que a dominante espacial das relações dialógicas não se opõe ao tempo nem elimina a história, mas tão-somente situa o movimento no presente de suas transformações e no momento de passagem de uma condição a outra, quando pontos de vista coexistem e contrapontos manifestam diferentes planos de realização na melhor tradição de um pensamento dialético. Afinal, é como espaço que os pontos de vista em interação e confronto constroem os planos dialógicos em que a personagem comparece com foco na forma exterior de suas ideias.

Assim entendemos a forma espacial da personagem cronotopicamente configurada não apenas pela dinâmica da relação entre autor e personagem como também pela articulação entre tempo e espaço em que a ênfase no segundo não significa eliminação do primeiro ${ }^{4}$. Ao formular as bases de sua poética histórica Bakhtin serve-se do conceito de cronotopo para designar o modo pelo qual o tempo pode ser focalizado como dimensão do espaço. Sob a dominância do espaço o tempo e tudo o que a ele se vincula, incluindo os seres e as personagens, podem ser dimensionados em sua magnitude temporal, isto é, em seus fluxos e devires onde toda forma é arquitetonicamente inacabada.

As novelas de Dostoiévski constituíram um laboratório experimental nesse sentido cuja consagração se daria nos grandes romances do autor. Munido de suas premissas filo-

4 Boris Schnaiderman discute com muitas ressalvas a afirmação de que Dostoiévski valorizou muito mais o espaço do que o tempo e enfatiza: "Não acredito que ele anule o tempo. 0 que ele anula é a sucessão linear dos acontecimentos." (SCHNAIDERMAN, 1982, p. 86). 
sóficas densamente formuladas nos anos de 1920, Bakhtin se mostra atraído pelas lutas que as personagens travam no nível das ideias de modo a construir sua autonomia discursiva à revelia do autor e em confronto com ele. Como forma espacial, o discurso das personagens entra em confronto com o discurso do autor e a arquitetura que sustenta o embate já não pertence a outro universo senão àquele espaço semiótico construído esteticamente pelo romance.

A forma visual construída como ponto de vista ou concepção de mundo elaborada num processo de autoconsciência é o que leva Bakhtin a definir a personagem de Dostoiévski como ideólogo (BAKHTIN, 1981, p. 65), como homem de ideias cuja representação define a qualidade artística da obra verbal e sua visualidade. Afinal, é no plano das ideias que as refrações tomam corpo enquanto criação reativa.

As descobertas de Bakhtin que equacionam personagem, espaço, discurso; ponto de vista, ideia, consciência; vivência, experiência, tempo, de modo a compor as imagens de relações em formas espaciais, estão na base da poética de Dostoiévski que abriu caminho para o amadurecimento da poética histórica, cumprindo a trajetória que parte da mais funda especulação filosófica sobre vivência e experiência, passa pela criação estética e assenta as bases do conhecimento e da história. Nesse deslocamento a imagem da linguagem é focalizada como forma espacial de um fluxo temporal do qual não pode ser desvinculada.

O princípio dostoievskiano da simultaneidade e da dramatização do espaço foi amplamente discutido por Bakhtin no seu estudo da forma espacial da personagem e nos embates que o processo de extraposição gera quando considerado num mesmo campo visual. Os vários deslocamentos da personagem da novela de Dostoiévski geram, contudo, diferen- 
tes dimensionalidades espaciais, a ponto de instigar reflexões sobre a condição do estrangeiro e a vivência do espaço que exerce a atração sobre os nativos não pelo lugar que representa mas pelas temporalidades que mobiliza, sobretudo no que diz respeito às invariáveis históricas das experiências cíclicas e de retorno.

Eis o caminho que nos leva de volta ao encontro de Lótman e a seu conceito de texto como precedente em relação à linguagem. Se Bakhtin tivesse apurado um pouco mais sua formulação seria dele a noção segundo a qual fora das relações dialógicas cronotópica e exotopicamente configuradas nenhum texto, nenhuma linguagem, nenhum discurso se constitui. Tal é a hipótese desafiadora que se coloca em nosso caminho investigativo.

Enquanto Bakhtin discute a espacialidade forjada segundo a enunciação de pontos de vista, os formantes do constructo discursivo de sua abordagem, Lótman ataca a ambivalência da condição que vincula o homem aos espaços de cultura que nem sempre estão em harmonia com a civilização. Pelo contrário: trata-se de observar um campo de forças que põe em xeque o conceito de civilização a partir de um domínio hegemônico e geopolítico que evidentemente se apoia numa hegemonia semiótica.

O personagem de Dostoiévski vivencia tal experiência e a traduz em relato de tensas relações dialógicas, quando concebe a exotopia da condição do ser estrangeiro e também quando descobre a ambivalência do russo europeu e eslavo, situado no fogo cruzado do progresso e do atraso medieval do povo russo. Na trama de tais relações dialógicas é o espaço quem projeta as tensões das formas espaciais que não se limitam ao indivíduo mas tem nele uma referência de manifestações cronotópicas e exotopicamente configuradas. Por 
conseguinte, a novela de Dostoiévski constrói a arquitetura das relações dialógicas que tanto podem ser dimensionadas como formas espaciais quanto como espaço semiótico. Disso tratou Lótman nos estudos sobre os textos da cultura como organismo da semiosfera.

Vale esclarecer, contudo, que ao examinar as ocorrências que vinculam o homem ao espaço, Lótman não estava se referindo a Dostoiévski nem citava Bakhtin. Todas as especulações que vou apresentar em minha análise correm por minha conta e risco. Devem ser entendidas, pois, como argumentos da hipótese apresentada.

\section{Experimentos teóricos de análise}

\subsection{A experiência do espaço na modelização de limites e fronteiras}

Os questionamentos do personagem na novela de Dostoiévski sustentam a noção de texto como tradução transformadora dos espaços em seu caminho de culturalização. Trata-se de um processo em que se assiste à transformação do espaço no confronto entre o próprio e o alheio, como se pode ler na síntese de Lótman.

Toda atividade do homem como homo sapiens está ligada a modelos classificatórios de espaço, a sua divisão entre "próprio" e "alheio" e à tradução dos variados vínculos sociais, religiosos, políticos, familiares, à linguagem das relações espaciais. (LOTMAN, I., 1996c, p. 83).

Na base da distinção entre próprio e alheio se erguem oposições como cultura e não-cultura; cultura e natureza; 
civilização e barbárie definidoras de estados de cultura que oscilam em intensidades em suas diferentes aparições. Na novela de Dostoiévski tal distinção abarcava o contraste entre a Europa europeia progressista e a Europa russa atrasada. Lótman, I. (1996c, p. 84), por sua vez, infere: “[...] a ideia de que cada espaço corresponde a seus habitantes - deuses, homens, uma força maligna ou seus sinônimos culturais - é característica inalienável da cultura.".

Longe de compor uma harmonia indissolúvel, o vínculo entre homem e espaço mostra o quanto as relações de luta são igualmente formas de preservação que Lótman concebeu como organização. Em seus estudos sobre o acabamento estrutural da obra artística, o vínculo é o que garante a constituição orgânica dos modelos de mundo em suas distintas manifestações. Para ele, na base de qualquer experiência do espaço situa-se um princípio de organização, até mesmo quando nada parece se articular numa ordenação sintagmática de elementos ou de questões. Lótman se refere ao pressuposto organizativo em processos de decomposição paradigmática em que as relações deslocam o princípio formativo do espaço para conjugações de outra natureza.

"Como tratar da infinitude do mundo e da finitude do homem?", se interroga Lótman. E, no entanto, ao enfrentar o dilema de tal relação, Lótman deriva o caráter modelizante das obras artísticas a partir das quais lhe foi possível pensar os sistemas culturais. "Sendo espacialmente limitada" - afirma ele - "a obra de arte representa o modelo de um mundo ilimitado." (LOTMAN, I., 1978, p. 349). 0 espaço assim modelizado ainda que limitado configura aquilo que o excede e se apresenta, em relação a ele, como um modelo universal.

O processo modelizante não é apenas um princípio organizativo do mundo como também a manifestação de relações 
dialógicas estruturais. Nesse sentido, agora segundo Lótman, a modelização do espaço a partir de limites tão elementares coloca "o papel modelizante muito particular das categorias de princípio e de fim" como "modelos culturais muito gerais" (LOTMAN, I., 1978, p. 352). Nele, a concepção do texto desempenha papel fundamental.

Construções espaciais ou temporais implicam, necessariamente, conjugações de diferentes trabalhos com noções como de "princípio" e "fim". Em seu estudo sobre o processo de modelização mitológica e religiosa, Lótman, I. (1981, p. 231-236) examina não apenas o papel da delimitação que tais categorias impõem aos modelos de mundo como também as fronteiras que porventura delas possam ser derivadas. Em ambos os casos, o processo modelizante se revela como uma forma de entrar em contato com "o problema da composição, da unidade construtiva do mundo e, portanto, do seu princípio ou do seu fim" (LOTMAN, I., 1981, p. 232). Antes de serem considerados termos de um par opositivo, "princípio" e "fim" são marcadores de possibilidades temporais como, por exemplo, “existente", “inexistente", “eterno" e, sobretudo, "histórico". Por isso, segundo Lótman, I. (1981, p. 232-233).

0 que tem princípio existe. Por isso, os estados que têm um princípio (lendas sobre os fundadores) contrapõem-se àqueles que podem invocar um antepassado. Daí a construção do primeiro texto histórico russo como uma série de narrações sobre os princípios.

Princípio e fim constituem diferentes funções modelizantes. Ao princípio compete a função histórica, explicativa e causal que rege a continuidade; já ao fim cabe marcar a significação com uma premissa conclusiva (LOTMAN, I., 1978, p. 352-359). Na mesma linha de raciocínio, Lótman entende os 
modelos ocupados em refletir sobre o fim do mundo não necessariamente de um ponto de vista escatológico, isto é, de destruição de tudo. Na verdade,

[...] o relato da extinção da vida terrena, enquanto criada, não por Deus, mas como consequência dum pecado original, só afirma a antítese de 'raiz boa' e 'raiz má'. Quem terá de ficar destruído é o mundo disforme, desprovido de valor, obra do diabo ou do homem, enquanto aquele querido por Deus é inquebrantável. (LOTMAN, I., 1981, p. 233).

O modelo de mundo que não marca o fim corresponde ao ponto de partida da história do gênero humano; enquanto que aquele que marca o fim "corresponderá à passagem da harmonia ao termo do processo histórico" (LOTMAN, I., 1981, p. 234). Culturas jovens, por exemplo, são marcadas pelo princípio e pela consciência de sua existência; ao passo que culturas antigas são marcadas pelo fim e pelo conflito (LOTMAN, I., 1981, p. 235).

Do ponto de vista da unidade composicional, a plasticidade das obras artísticas desenvolve experiências de espaço em que os limites se tocam e se encontram em fronteiras. Trata-se de observar modelos de mundo em que o que é infinito em sua natureza se transforma em algo finito, colocando em evidência a dinâmica do espaço semiótico no confronto do dualismo de sua unidade. As experiências de espaço do ponto de vista do encontro estrutural em fronteiras exploram possibilidades criativas que problematizam os confrontos entre acabamento e inacabamento; limitado e ilimitado; princípio e fim.

Ora os modelos espaciais do mundo não são formas espaciais acabadas, pelo contrário, são emergências em constante movimento de atualização. Lótman viu nesse movimen- 
to o fundamento da cultura e a razão de sua permanência e continuidade. Sua questão elementar era: o que garante esse movimento gerador de modelos organizativos da sobrevivência cultural? Para Lótman a razão da permanência de tal dinamismo corresponde à existência de um mecanismo de interação que não apenas é anterior à linguagem como também a constitui. Esse mecanismo ele denominou simplesmente de TEXTO e o situou na base de seu pensamento semiótico. Lótman duvidava de que qualquer forma isolada, até mesmo a linguagem única, fosse suficiente para garantir o fenômeno da cultura.

A ideia de que o ponto de partida de qualquer sistema semiótico não seja o simples signo isolado (a palavra), mas a relação entre, pelo menos, dois signos nos leva a pensar de modo distinto as bases fundamentais da semiose. 0 ponto de partida não pode ser o modelo isolado mas sim o espaço semiótico. (LOTMAN, I., 1999, p. 230, grifo do autor).

Temos aqui posta a questão que apresentamos inicialmente: a radicalidade da noção lotmaniana de texto em oposição à noção de discurso restrita ao mundo verbal. Quando Lótman refere-se a TEXTO ele está valorizando modelos de mundo que se reportam a gestos civilizacionais que se perdem no tempo, ou melhor, "escoam no tempo" cronotópica e exotopicamente e, portanto, se encarregam de constituir espaço semiótico para a geração de novos textos ou novas formações culturais. 0 TEXTO a que se refere Lótman corresponde muito mais à função cultural das relações dialógicas amplas e imprevisíveis do que a um produto ou a uma realização de uma civilização. Enquanto tal, o texto cumpre sua função de definir a cultura pela interação e pelo encontro cultural não pelo domínio de uma formação ou um sistema em detrimento de outro. 
Livre da hegemonia semiótica do modelo estritamente verbal, o texto se reporta livre e plenamente ao espaço semiótico das relações dialógicas. Um texto concebido nos limites de articulações internas do signo isolado parece-lhe um dissenso.

Tal como o personagem da novela de Dostoiévski, mas num tom de radicalidade e disposto a reverter as regras do jogo da hegemonia semiótica na definição civilizacional, Lótman se indaga porque tudo o que é considerado civilização e desenvolvimento toma como marco o logos grego e sua expressão mais elementar: o sistema de escrita dominado pelo alfabeto ocidental. Para Lótman, estamos de tal forma condicionados pela ideia de que "toda a cultura conhecida pela ciência europeia está baseada na escritura" que é "impossível imaginar-se uma cultura ágrafa desenvolvida" (LOTMAN, I., 1998, p. 81). E, para nossa surpresa, Lótman, I. (1998, p. 82) contesta:

0 nexo que liga a existência da civilização desenvolvida, a sociedade de classes, a divisão do trabalho e o alto nível dos serviços sociais e da técnica de construção, irrigação, etc., condicionado por elas à existência da escritura, parece tão natural, que as possibilidades alternativas são rechaçadas a priori. Baseando-nos no amplo material que nos foi dado realmente, poderíamos reconhecer esse nexo como uma lei universal da cultura se não fosse pelo enigmático fenômeno das civilizações pré-incaicas sul-americanas.

Tomar civilizações ágrafas como um caminho explicativo para uma outra possibilidade de desenvolvimento histórico abre a noção de texto para sistemas semióticos diversos daqueles consagrados por uma certa tradição etnocêntrica. Vislumbram-se traços diferenciais que distinguem as culturas e, ao mesmo tempo, geram toda uma dinâmica de modelos 
de mundo assentados por outras premissas. Assim sustenta o raciocínio que o levaria a especular sobre o texto como tradução de forças culturais em luta num espaço de fronteiras. Nessa especulação emerge uma outra vertente fundamental: o estudo sobre a tipologia das culturas não como singularidades civilizacionais, nacionais ou linguísticas, noção consagrada pelo euro e etnocentrismo, mas como textos ou modelos informacionais ocupados com a permanência e o desenvolvimento futuro (LOTMAN, I., 1998, p. 84). Com base nesse modelo tipológico Lótman concebe o espaço dialógico da cultura no limiar das muitas fronteiras que se articulam num campo de forças nem sempre convergentes.

\subsection{Fronteiras e relevos textuais da tradução no espaço semiótico}

Uma das linhas de força do conceito de fronteira reside em sua capacidade de colocar em destaque sistemas de relações espaciais nem sempre evidentes. Nisso reside igualmente o valor intrínseco de sua função modelizante: a fronteira mostra a possibilidade de deslocamento, de passagem de uma dimensão a outra, de tradução, que tanto pode ser uma língua quanto um espaço fisicamente configurado. Com isso, toda fronteira situa confrontos e se alimenta de atritos longe de ser uma linha divisória que delimita pontos em relação. Disso tratou Lótman ao compreender o próprio conceito de espaço geográfico como construção de um tópos criador de topologias.

Se, por topologia, entendem-se as relações não circunscritas a lugares, mas aquelas capazes de atravessar temporalidades e espacialidades, são topológicas as relações dialógicas de exotopia. Por exemplo: a ambivalência do estrangeiro 
enquanto ser e enquanto espaço de visitação narrado pelo personagem na novela de Dostoiévski em confronto com os modelos de espaço de seu país, a Rússia medieval e rural; de sua São Petersburgo como cidade europeizada.

Com esse exemplo em mente, passemos ao experimento de análise que nos é dado pela topologia da consciência do homem medieval. Lótman observa o quão importante foi para a sua constituição a distinção opositiva entre a vida terrena e a vida celeste, o que interferiu até mesmo no conceito de espaço geográfico não limitado à topografia. Para um certo modo de operar a consciência medieval, a Terra é percebida tanto como sede da vida terrena como campo que abriga a oposição terra-céu, e, por conseguinte, assume um significado ético-religioso estranho ao conceito geográfico moderno. Insere-se numa escala vertical de valores cujo grau mais elevado encontra-se no céu e o mais baixo no inferno (LOTMAN, J., 1975, p. 183). Atente-se para o fato de que céu e inferno não são explorados como lugares, mas como exotopias: espaços de relações topologicamente configuradas.

Ao tomar o espaço geográfico como uma variedade de conhecimento ético, Lótman observa que a vida terrena se torna de fato um espaço de transição - uma peregrinação de um lugar pecaminoso para um lugar santo e eterno para o qual se encaminha com a morte num deslocamento geográfico-espacial (LOTMAN, J., 1975, p. 186). Assim, segundo suas inferências, a utopia russa medieval implicava a existência de uma geografia e de um clima próprios, de um diferente mundo vegetal e animal, que oferecia ao viajante distintos graus de virtude. Paraíso e inferno como inclusos no espaço geográfico constituíam uma ética espacial. A terra santa possui um clima favorável e por consequência a alegria que constitui uma norma de vida, não sua transgressão (LOTMAN, J., 1975, p. 192). 
Baseado em raciocínio equivalente, Lótman elabora as formulações sobre o espaço semiótico da semiosfera cuja dinâmica se alimenta de irregularidades, heterogeneidades e assimetrias como as forças que presidem a geração de diferentes línguas e linguagens que vinculam homens aos espaços e nem por isso impedem os encontros dialógicos das culturas.

Com base nesse raciocínio é possível problematizar a noção de fronteira a partir do espaço semiótico constituído quando da expansão europeia ultramarina que desembocou no continente americano. Assistiu-se, por um lado, à emergência de novos textos de cultura; por outro, a conflitos de toda ordem uma vez que os novos textos não cabiam numa única língua. A irredutibilidade linguística não apenas desafiou o legado histórico da civilização dominante como também desestabilizou o quadro em que as línguas europeias se consagraram como agentes fundamentais na definição das culturas do novo continente. Contra esse cenário, emergiram as relações dialógicas responsáveis pela amplificação dos sistemas comunicativos, pela expansão e geração de novas linguagens. Cumpre-se uma revisão do pressuposto de Lótman a respeito da hegemonia do conceito civilizacional consagrado pela matriz logocêntrica em nome da valorização do conceito ampliado de texto.

Há que se observar, de saída, a constituição de um espaço semiótico de fronteira cuja trama é tecida pelo que corre pelo interior e pelo exterior do continente europeu. A aventura do além-mar tornou-se o grande marco do processo de ocidentalização do planeta que a cultura letrada da escrita alfabética ocidental construiu como seu mais forte legado. Internamente a escalada linguística se encarregou tanto da expansão e multiplicação de línguas a partir do latim quanto 
da instituição das divisões dos Estados nacionais. Quando o movimento de expansão ultramarina iniciado já no século XV avançou para a ampliação dos limites geográficos, acreditavase que o domínio linguístico e cultural pudesse ser implantado dentro de outras circunscrições geopolíticas. Experiências históricas a partir de outras relações topológicas do espaço de fronteiras levaram os acontecimentos do além-mar para outras projeções e se adentraram para um espaço informacional radicalmente outro, desconhecido e imprevisível.

Com a descoberta de novos continentes processou-se uma informação nova, como afirmara Lótman em seu entendimento do mecanismo semiótico da cultura. Novos algoritmos do espaço informacional entram na composição do texto de cultura. Para além do próprio e do alheio vimos emergir a fronteira - uma terra estrangeira - de um espaço projetado em função de interesses políticos de dominação e, por conseguinte, tensionado pelo encontro com o outro. Espaço aqui não enfatiza o lugar, mas o limiar em que o jogo de relações se orienta pelos mecanismos culturais de multiplicação dos contatos, das línguas, linguagens e processos de comunicação cultural entram em confronto com os lugares e com suas delimitações de poder e de confrontos. A principal consequência desse fato é a consolidação da fronteira como espaço ambivalente: une e separa o próprio e o alheio. Nesse sentido, “a duplicação do mundo na palavra e a do homem no espaço forma o dualismo semiótico de partida" (LOTMAN, I., 1996c, p. 85). Por conseguinte, os homens com suas linguagens e culturas transitam de um lugar para o outro, instauram confrontos no interior dos limites, tensionando as linhas que só aparentemente separam o próprio do alheio. A cultura assim focalizada mostra-se um espaço de encontros, confrontos e, sobretudo, de fronteiras entre superfícies e linguagens culturais. 
Ao colocar a ênfase no encontro em confronto, tanto no interior de uma cultura quanto entre diferentes culturas, o conceito de fronteira é dimensionado semiótica e culturalmente e não apenas por uma delimitação geográfica. Na verdade, a própria definição geopolítica passa a ser entendida como dinâmica de um espaço cultural semiotizado pelas línguas expandidas e por diferentes sistemas de signos da comunicação cultural desenvolvidos no ocidente, sobretudo, a partir da escrita alfabética.

Ao continuum das relações espaciais, os sistemas de signos da cultura opõem e deixam emergir confrontos, o que sugere a configuração de uma singular dinâmica espacial da semiosfera. Trata-se, sobretudo, de um espaço de cultura que se entende como fronteira. Nele tanto os seres quanto suas construções, tais como as línguas e os meios de comunicação em geral, dinamizam fronteiras em níveis de distintas constituições, direções e temporalidades, orientados que são pelos encontros culturais. Quanto mais diversificados se revelam os encontros e quanto mais variáveis perturbadoras em confronto, mais complexo se torna o espaço. Imerso na semiosfera, o espaço semiótico assume o funcionamento dinâmico de um sistema liminar. Os encontros culturais por sua vez definem a fronteira como episteme fundamental dos estudos das relações entre comunicação e espaço, base do conceito de texto como modelo de mundo.

\section{Proposições conclusivas}

No início dessa exposição referi-me ao fato de a noção de espaço semiótico fundar uma percepção das relações dialógicas que estão longe de se limitar ao discurso circunscrito à esfera 
logocêntrica. Quando Lótman entende o texto como problema semiótico por excelência, ele propõe uma força cuja magnitude de realizações cobre um universo amplo e diversificado de sistemas semióticos e de campos em luta. Podemos dizer agora que Lótman descobriu no texto de cultura a potencialidade que extrapola o limite discursivo das línguas e desloca o foco para os confrontos que se operam na linha de fogo da tradução de um espaço semiótico que não se limita ao campo verbal e visual em que reina a palavra. Pelo contrário, procura abarcar experiências de transformação informacional que alimentam a cultura e sua permanência como forma de vida no universo.

Em nossa indagação inicial também incluímos uma pergunta sobre qual seria a contribuição de Lótman para os estudos do discurso. Arriscamos dizer que seu mais forte legado reside na insistência em questionar posicionamentos hegemônicos numa tradição cultural em nome do movimento transformador em espaços informacionais. A radicalidade de suas ampliações sobre o conceito de texto torna-se o exemplo vivo de tal premissa. Ao trazer para o debate o processo da tradução não como a simples troca da input e output ou codificação e decodificação, mas como dramaticidade do confronto de esferas de intraduzibilidade entre sistemas de signos que não atuam apenas no eixo do sistema verbal, Lótman nos convida a pensar o espaço semiótico da semiosfera na vivacidade de seu dinamismo. Suas inferências sobre a importância dos algoritmos fundamentais da semiose textual não restritos a posturas etnocêntricas mostram-se plenamente favoráveis à historicidade das bases formadoras da cultura brasileira. Não apenas o texto pode ser dimensionado na dinâmica de nossas fronteiras multiculturais nem sempre evidentes, como também a própria dinâmica da semiosfera pode ser apreendida como mecanismo de tradução. 
Sabemos que o conceito de semiosfera lotmaniano tem sido considerado como restritivo na análise de sistemas específicos. Por exemplo: semiosfera da linguagem, semiosfera dos meios de comunicação, semiosfera da música etc. Tais usos restritivos guardam, contudo, um risco que merece ser dimensionado: colocar um sistema cultural no centro irradiador de uma hierarquia, eliminando a continuidade que as fronteiras lutam por manter. 0 raciocínio subjacente ao dinamismo na semiosfera propõe o conceito de fronteira como processo de tradução exatamente para contestar a linha divisória que polariza centro e periferia e por garantir o continuum semiótico. Na verdade, quando se focaliza o sistema cultural imerso na semiosfera o que se observa é a luta pela sobrevivência no espaço de fronteira. Se existe hierarquia como observa Lótman esta é uma hierarquia complexa visto que mantém o espírito de luta e confronto que evita a hegemonia. Talvez esse seja um bom início para se situar o discurso como um problema semiótico que certamente pode ser examinado pelo viés das formulações de Iúri Lótman.

\section{REFERÊNCIAS}

BAJTÍN, M. M. Estética de la creación verbal. Tradução de T. Bubnova. 3. ed. Mexico: Siglo Veintiuno, 1989.

. Formas de tempo e de cronotopo no romance. Ensaio de poética histórica. In: Questões de literatura e de estética. A teoria do romance. Tradução de A. F. Bernardini et al. São Paulo: UNESP, 1988.

. Problemas da poética de Dostoiévski. Tradução de P. Bezerra. Rio de Janeiro: Forense-Universitária, 1981. 
DOSTOIÉVSKI, F. Notas de inverno sobre impressões de verão. In: Memórias do subsolo e outros escritos. Tradução de B. Schnaiderman. São Paulo: Paulicéia, 1992.

IVANOV, V. V. et al. Theses on the Semiotic Study of Cultures. Tradução de S. Salupere. Tártu: University of Tartu, 1998. [Teses para uma análise semiótica da cultura (uma aplicação aos textos eslavos). Tradução de G. T. Santos. In: MACHADO, I. Escola de semiótica. A experiência de Tártu-Moscou para o estudo da cultura. São Paulo: Fapesp; Ateliê Editorial, 2003.]

LOTMAN, I. M. Algunas ideas sobre la tipologia de las culturas. La semiosfera. Semiótica de la cultura, del texto, de la conducta y del espacio. Tradução de D. Navarro. Madrid: Cátedra, 1998.

Acerca de la semiosfera. La semiosfera. Semiótica de la cultura y del texto. Tradução de D. Navarro. Madrid: Cátedra, 1996a.

. La semiótica de la cultura y el concepto de texto. La semiosfera. Semiótica de la cultura y del texto. Tradução de D. Navarro. Madrid: Cátedra, 1996b.

. El texto y el poliglotismo de la cultura. La semiosfera. Semiótica de la cultura y del texto. Tradução de D. Navarro. Madrid: Cátedra, 1996c.

. La semiosfera. L'asimmetria e il dialogo nelle strutture pensanti. Tradução de S. Salvestroni. Venezia: Marsilio, 1984.

. Valor modelizante dos conceitos de "fim" e "princípio" (1970). In LOTMAN, I.; USPENSKII, B.; IVANOV, V. V. Ensaios de semiótica soviética. Tradução de V. Navas e S. T. Menezes. Lisboa: Horizonte, 1981. 
A estrutura do texto artístico. Tradução de M. C. V. Raposo e A. Raposo. Lisboa: Estampa, 1978.

LOTMAN, I. M.; PIATIGORSKI, A. M. El texto y la función. In LOTMAN, I. M. La semiosfera. Semiótica de la cultura, del texto, de la conducta y del espacio. Tradução de D. Navarro. Madrid: Cátedra, 1998.

LOTMAN, J. M. Il concepto di spazio geografico nei testi medievali russi. In LOTMAN, J. M.; USPENSKIJ, B. A. Tipologia della cultura. Tradução de M. B. Faccani e outros. Milano: Bompiani, 1975.

LOTMAN, M. A Few Notes on the Philosophical Background of the Tartu School of Semiotics. European Journal for Semiotic Studies, v. 12, n. 1, 2000, p. 23-46.

LOTMAN, Y. M. Cultura y explosión. Lo previsible y lo imprevisible en los procesos de cambio social. Tradução de Delfina Muschietti. Barcelona: Gedisa, 1999.

. The Text as a Meaning-generating Mechanism. In: Universe of the Mind. A Semiotic Theory of Culture. Tradução de A. Shukman. Bloomington and Indianapolis: Indiana University Press, 1990a, p. 9-119.

.The Semiosphere. In: Universe of the Mind. A Semiotic Theory of Culture. Tradução de A. Shukman. Bloomington and Indianapolis: Indiana University Press, 1990b. p. 121214.

MACHADO, I. A questão espaço-temporal em Bakhtin: cronotopia e exotopia. In Círculo de Bakhtin: teoria inclassificável. PAULA, L. de; STAFUZZA, G. (Org.). São Paulo: Mercado de Letras, 2010. 
. O filme que Saussure não viu: o pensamento semiótico de Roman Jakobson. São Paulo: Fapesp; Vinhedo: Horizonte, 2008.

SCHNAIDERMAN, B. Dostoiévski prosa e poesia. São Paulo: Perspectiva, 1982.

Artigo recebido em janeiro de 2015 e aprovado em junho de 2015.

Disponível em: http://seer.fclar.unesp.br/casa 